\title{
Assessment of anterior segment parameters in children with obesity
}

\author{
Semra KOCA ${ }^{1}$, Melikşah Keskin ${ }^{2}$, Murat Sinan SARICAOĞLU ${ }^{3}$, Serkan KOCA 4 , Ayten Kocaman Bulut ${ }^{3}, Z_{\text {ehra Aycan }}^{5}$ \\ ${ }^{1}$ Department of Ophthalmology, Denizli State Hospital, Denizli, Turkey \\ ${ }^{2}$ Clinics of Pediatric Endocrinology, Dr. Sami Ulus Training and Research Hospital of Women's and Children's Health and Diseases, Ankara, Turkey \\ ${ }^{3}$ Department of Ophthalmology, AnkaraNumune Training and Research Hospital, Ankara, Turkey \\ ${ }^{4}$ Clinics of Pediatric Endocrinology, Denizli State Hospital, Denizli, Turkey \\ ${ }^{5}$ Department of Paediatric Endocrinology, School of Medicine, Ankara University, Ankara, Turkey
}

\begin{abstract}
Purpose: To evaluate whether Pentacam-Scheimpflug imaging of anterior segment parameters are different in obese children than in normal children.

Methods: This prospective comparative study was conducted using a total of 40 obese children and 41 healthy children. All subjects underwent comprehensive ophthalmologic examinations, including refraction, intraocular pressure, anterior segment and fundus examination. In addition, central corneal thickness (CCT), anterior chamber depth (ACD), anterior chamber volume (ACV), and anterior chamber angle (ACA) values were measured using a Pentacam-Scheimpflug camera.

Results: The mean CCT, ACD, ACV, and ACA values were similar in obese and healthy pediatric individuals. The correlation analysis revealed no statistically significant influence of BMI, age, and sex for any measurements of anterior segment parameters in the obese and control groups.
\end{abstract}

Conclusion: These results may be helpful to the clinician in assesment of diagnosis and follow-up of obese children with additional ocular pathologies.

\section{Introduction}

Obesity is a major public health problem increasing at staggering rates in many countries. Childhood obesity has more than doubled in children and quadrupled in adolescents over the past 30 years. In 2012, more than one third of children and adolescents were overweight or obese. The impact of obesity on health is widespread and the deleterious effects of obesity on the cardiovascular and metabolic systems are well documented. However, the potential ocular effects of obesity are less well known. Different studies have identified an association between obesity and ocular hypertension, cataract, age-related macular disease, diabetic retinopathy, and diseases of oculomotor nerves [1-7].

Although obesity is a serious public health issue in children and adolescents, all previous investigations were carried out with adult subjects.

A review of anterior segment parameters like central corneal thickness (CCT), corneal volume (CV) anterior chamber depth (ACD), anterior chamber volume (ACV), anterior chamber angle (ACA) play a role in certain anterior segment anomalies and influence surgical decisions [8]. These anterior segment parameters were measured with a Pentacam, a noninvasive and three-dimensional corneal topographer, providing an evaluation of the anterior segment.

This study aimed to assess the anterior segment parameters with the Pentacam rotating Scheimpflug camera in obese children and then compare these results with a group of normal children.

\section{Materials and methods}

\section{Study population and design}

This prospective and comparative study, consisting of obese and healthy pediatric individuals younger than 18 years old, was performed at the Clinics of Pediatric Endocrinology, Dr. Sami Ulus Training and Research Hospital of Women's and Children's Health and Diseases, and Department of Ophthalmology, Ankara Numune Training and Research Hospital in Ankara, Turkey. The study was approved by the local ethics committee and conducted in accordance with the ethical principles described by the Declaration of Helsinki. Informed consent to participate in the research study was obtained from a parent or legal guardian.

Body Mass Index (BMI) is defined as a person's weight in kilograms divided by the square of the height in meters, relative to gender and age, and is used to screen for obesity, overweight, healthy weight, or underweight. In a group of children ages 2 to 19 , those with a BMI higher than 95 percent, assessed by age- and sex-specific percentiles, are described as obese by the U.S. Centers for Disease Control and

*Correspondence to: Semra Koca, Şehit Mustafa Baş Caddesi 11/2 Aydınlıkevler Altındağ/ ANKARA postal code: 06130, Turkey; tel: +90 54385756 23; Fax: +90 31231143 40; E-mail: drsemrakara68@hotmail.com

Key words: anterior segment parameters, children, obesity, pentacam

Received: February 01, 2019; Accepted: February 14, 2019; Published: February 18,2019 
Prevention [9]. According to the WHO Reference 2007 (ages 5 to 19), obesity is defined as having a BMI greater than two standard deviations above the WHO growth standard median [10]. We used all of these nomograms at every stage of the study, and the standard deviation score measurements were especially useful. The study group included 40 randomly selected obese children referred to us through the Department of Pediatric Endocrinology. The control group consisted of 41 randomly selected non-obese, healthy children. Only the readings of the right eyes were used for analysis. None of the control subjects had any medical history. Exclusion criteria for both groups included: any systemic diseases (hypertension, diabetes mellitus, thyroid disorders, etc.); orbital and ocular diseases (previously known glaucoma and uveitis, ocular trauma, history of intraocular surgery); best corrected visual acuity (BCVA) worse than 20/20; high spherical $> \pm 3$ dioptri or cylindrical $>1.5$ diopter refractive error; and a history of wearing contact lenses. All participants underwent a detailed ophthalmologic examination including refractive error; BCVA; slit lamp and dilated fundus examination; and intraocular pressure measured by applanation tonometry and Pentacam Scheimpflug camera imaging.

\section{Pentacam-Scheimpflug camera measurements}

The anterior segment parameters were evaluated using the Pentacan rotating Scheimpflug camera (Oculus Inc. Germany) by the same person, and these evaluations were repeated until an acceptable quality image was obtained. This device can perform a complete measurement of the anterior eye segment in less than two seconds, combining a rotating Scheimpflug camera with a static camera to acquire multiple photographs of the anterior segment of the eye. Measurements were made in darkness to standardize all measurements for each subject. CCT, ACD, ACV, ACA measurements were extracted from the obtained topographic and pachymetric maps for statistical analysis.

\section{Statistical analysis}

Statistical analysis was performed using IBM SPSS for Windows Version 21.0 Package Programme. Quantitative variables were reported as mean \pm standard deviation (SD) or median [min - max], while the qualitative variables were summarized as number and percent. The normality and homogeneity of variance of the data was confirmed. For the comparison of the quantitative measurement values of the two groups, the Student's t test was applied to the values complying with the normal distribution, and the Mann-Whitney $U$ test was applied to those not complying with the normal distribution. The chi-square or Fisher's exact test was used for the comparison of the qualitative data. Spearmen or Pearson correlation tests were used for the correlation analysis. Statistical significance was defined as a p value of 0.05 .

\section{Results}

Table 1 shows the characteristics of the obese and control groups and the anterior segment parameters. The obese group included 25 female subjects and 15 male subjects. The mean age was $13.1 \pm 2.2$ years, in a range from 9 to 16 years old. The control group included 23 female subjects and 18 male subjects, and the mean age was $13.4 \pm 2.8$ years, in a range of 8 to 18 years old. There was no statistically significant difference between the two groups in terms of age and sex. The BMI was significantly higher in the study group $(\mathrm{p}=<0.001)$. The mean intraocular pressure ( IOP) values were 15.2 [10 - 22] $\mathrm{mmHg}$ in the control group and $16.1[10-23] \mathrm{mmHg}$ in the obese group $(\mathrm{p}=0.103)$. The CCT, ACD, ACV, and ACA values were $566.7 \pm 36.1 \mu \mathrm{m}, 3.0 \pm 0.3$ $\mathrm{mm}, 183.6 \pm 40.9 \mathrm{~mm} 3,39.7 \pm 6.4^{\circ}$, respectively, in the control group.
Table 1. Statistical comparison of demographic and ocular characteristics of study participants

\begin{tabular}{|c|c|c|c|}
\hline & $\begin{array}{c}\text { Control group } \\
(\mathbf{n = 4 1})\end{array}$ & $\begin{array}{c}\text { Obese group } \\
(\mathbf{n = 4 0 )}\end{array}$ & P \\
\hline Age (years) & $13,4 \pm 2,8$ & $13,1 \pm 2,2$ & 0,636 \\
\hline $\begin{array}{c}\text { Sex (female/male) } \\
\mathrm{n}(\%)\end{array}$ & $\begin{array}{c}23 / 18 \\
(\% 56 / \% 44)\end{array}$ & $\begin{array}{c}25 / 15 \\
(\% 62 / \% 38)\end{array}$ & 0,719 \\
\hline Height $(\mathrm{cm})$ & $155,7 \pm 12,3$ & $159,6 \pm 13,9$ & 0,188 \\
\hline Weight $(\mathrm{kg})$ & $49,9 \pm 14,9$ & $79,6 \pm 18,0$ & $<0,001$ \\
\hline $\mathrm{BMI}\left(\mathrm{kg} / \mathrm{m}^{2}\right)$ & $20,2 \pm 3,6$ & $30,7 \pm 3,1$ & $<0,001$ \\
\hline IOP $(\mathrm{mm} \mathrm{Hg})$ & $15.2[10-22]$ & $16.1[10-23]$ & 0,216 \\
\hline $\mathrm{CCT}(\mu \mathrm{m})$ & $566,7 \pm 36,1$ & $553 \pm 41,0$ & 0,134 \\
\hline $\mathrm{ACD}(\mathrm{mm})$ & $3,0 \pm 0,3$ & $3,1 \pm 0,3$ & 0,352 \\
\hline $\mathrm{ACV}\left(\mathrm{mm}{ }^{3}\right)$ & $183,6 \pm 40,9$ & $184,4 \pm 35,4$ & 0,926 \\
\hline $\mathrm{ACA}\left({ }^{\circ}\right)$ & $39,7 \pm 6,4$ & $40,1 \pm 5,5$ & 0,781 \\
\hline
\end{tabular}

BMI: body mass index, IOP: intraocular pressure, CCT: central corneal thickness, ACD anterior chamber depth, ACV: anterior chamber volume, ACA: anterior chamber angle, Values are described as mean $\pm \mathrm{SD}$ or median [min - max]

Table 2. Correlation between age and anterior segment parameters

\begin{tabular}{|c|c|c|c|c|}
\hline & \multicolumn{2}{|c|}{ Control group } & \multicolumn{2}{c|}{ Obese group } \\
\hline & $\mathbf{r}$ & $\mathbf{p}$ & $\mathbf{r}$ & $\mathbf{p}$ \\
\hline CCT & $-0,033$ & 0,836 & $-0,056$ & 0,732 \\
\hline ACD & $-0,221$ & 0,166 & $-0,074$ & 0,655 \\
\hline ACV & $-0,181$ & 0,257 & $-0,144$ & 0,382 \\
\hline ACA & 0,011 & 0,946 & 0,277 & 0,088 \\
\hline
\end{tabular}

$\mathrm{CCT}$ : central corneal thickness, $\mathrm{ACD}$ : anterior chamber depth, $\mathrm{ACV}$ : anterior chamber volume, ACA: anterior chamber angle

Table 3. Correlation between sex and anterior segment parameters

\begin{tabular}{|c|c|c|c|c|c|c|}
\hline & \multicolumn{3}{|c|}{ Control group } & \multicolumn{3}{c|}{ Obese group } \\
\hline & $\begin{array}{c}\text { Female } \\
(\mathbf{n = 2 3 )}\end{array}$ & $\begin{array}{c}\text { Male } \\
(\mathbf{n = 1 8})\end{array}$ & $\mathbf{p}$ & $\begin{array}{c}\text { Female } \\
(\mathbf{n = 2 5})\end{array}$ & $\begin{array}{c}\text { Male } \\
(\mathbf{n = 1 5})\end{array}$ & $\mathbf{p}$ \\
\hline CCT & $563,7 \pm 33,2$ & $568,8 \pm 40,3$ & 0,657 & $554,0 \pm 39,2$ & $551,3 \pm 45,1$ & 0,841 \\
\hline ACD & $3,0 \pm 0,4$ & $3,1 \pm 0,3$ & 0,428 & $3,0 \pm 0,3$ & $3,2 \pm 0,3$ & 0,097 \\
\hline ACV & $176,1 \pm 42,7$ & $193,2 \pm 37,3$ & 0,189 & $174,7 \pm 22,1$ & $200,0 \pm 46,6$ & 0,064 \\
\hline ACA & $39,3 \pm 6,1$ & $40,2 \pm 6,9$ & 0,680 & $39,7 \pm 4,4$ & $40,6 \pm 7,1$ & 0,631 \\
\hline
\end{tabular}

CCT: central corneal thickness, ACD: anterior chamber depth, ACV: anterior chamber volume, ACA: anterior chamber angle

Table 4. Correlation between BMI and anterior segment parameters

\begin{tabular}{|c|c|c|c|c|}
\hline & \multicolumn{2}{|c|}{ Control group } & \multicolumn{2}{c|}{ Obese group } \\
\hline & $\mathbf{r}$ & $\mathbf{p}$ & $\mathbf{r}$ & $\mathbf{p}$ \\
\hline CCT & 0,302 & 0,061 & 0,144 & 0,374 \\
\hline ACD & $-0,112$ & 0,487 & $-0,303$ & 0,061 \\
\hline ACV & 0,018 & 0,913 & $-0,171$ & 0,299 \\
\hline ACA & $-0,042$ & 0,793 & 0,160 & 0,330 \\
\hline
\end{tabular}

$\mathrm{CCT}$ : central corneal thickness, $\mathrm{ACD}$ : anterior chamber depth, $\mathrm{ACV}$ : anterior chamber volume, ACA: anterior chamber angle

In obese group, the CCT, ACD, ACV, and ACA values were $553.0 \pm 41.0$ $\mu \mathrm{m}, 3.1 \pm 0.3 \mathrm{~mm}, 184.4 \pm 35.4 \mathrm{~mm} 3,40.1 \pm 5.5^{\circ}$, respectively. There was no significant difference $(\mathrm{p}>0.05)$ in the mean CCT, ACD, ACV, and ACA values.

The correlation between BMI, age, sex, and the anterior segment parameters are shown in Tables 2-4. The correlation analysis revealed no statistically significant influence of BMI, age, and sex for any measurements of the anterior segment parameters in the control or obese groups.

\section{Discussion}

The assessment of anterior segment parameters is an important part of ophthalmic examination. Anterior segment parameters were 
quantitatively assessed using a non-contact method with the patient in a sitting position [11]. Therefore, this assessment has proven to be a valuable tool for visualizing and monitoring anterior-chamber structures in several diseases. In addition, the quantitative documentation of any alterations in these anterior segment parameters may provide useful information that contributes towards our understanding of ocular dynamics.

A number of factors such as age, race, gender, refractive error, and corneal curvature may affect CCT. However, some studies have found that gender, age, mean refractive error, and mean cylindrical refractive error had no significant effect on CCT [12-15]. ACD, ACA, and ACV were correlated with age, gender, and pupil diameter, in accordance with some previous studies [16-18]. A multiple regression model suggests that age, rather than gender or pupil diameter, is the main factor affecting ACD.

There is less data addressing the relationship between obesity and eye diseases, although there have been some mechanical and vascular pathophysiological mechanisms. According to vascular theory, abnormal ocular blood flow and perfusion instability secondary to alternations in autonomic and endothelial dysfunction may cause poor vascular supply[19]. With regard to the mechanical theory, obesity has been postulated to cause excessive intraorbital adipose tissue, increased blood viscosity, and increased episcleral venous pressure [20-24]. Increased blood viscosity and increased resistance at small vessels can cause transient or permanent ischemia. Obesity is defined as having excess body fat [25]. In addition to increased fat mass, the consequences of obesity develop as a consequence of morphological and functional changes within the adipose tissue. Retrobulbar adipose tissue (RAT) extends from the apex of the orbit to the eyelids and surrounds the eyeball, muscles, nerves, and blood vessels. The mean RAT tissue volume measured by magnetic resonance imaging was significantly higher in obese subjects than in normal weight subjects [26]. RAT could be placed into the mechanism of 'mass effect', since its presence can directly or indirectly influence anterior segment parameters.

Although obesity is a serious and widespread public health issue in children and adolescents, there are no studies examining anterior segment parameters in obese pediatric population. This study aimed to sort out the effect of obesity on anterior segment parameters. A study including 34 normal and obese subjects showed that ACV, ACA, and CCT were not significantly different between the groups, while the mean ACD in obese subjects was significantly lower than in control subjects, and ACD and ACA were negatively correlated with BMI [27]. We determined that the mean CCT, ACD, ACV, and ACA values were similar in obese and healthy pediatric individuals. A correlation analysis revealed no statistically significant influence of BMI, age, and sex for any measurements of anterior segment parameters in the control or obese groups. The limitations of this study were the mostly uniform ethnic group (Turkish), the relatively small number of cases, and the lack of axial length measurements.

In summary, these results may be beneficial in the clinical assessment of obese patients with additional ocular pathologies (e.g corneal diseases, glaucoma). Further studies comparing these parameters with that of obese patients are necessary.

\section{Acknowledgement}

The authors did not receive any financial support from any public or private source. The authors have no financial or proprietary interest in a product, method or material described here.

\section{References}

1. Cheung N, Wong TY (2007) Obesity and eye diseases. Surv Ophthalmol 52: 180-195. [Crossref]

2. Jaén Díaz J, Sanz Alcolea I, López De Castro F, Pérez Martínez T, Ortega Campos P, et al. (2001) [Glaucoma and ocular hypertension in primary care]. Aten Primaria 28: 23-30. [Crossref]

3. Mori K, Ando F, Nomura H, Sato Y, Shimokata H (2000) Relationship between intraocular pressure and obesity in Japan. Int J Epidemiol 29: 661-666. [Crossref]

4. Teuscher AU, Meienberg O (1985) Ischaemic oculomotor nerve palsy. Clinical features and vascular risk factors in 23 patients. $J$ Neurol 232: 144-149. [Crossref]

5. Clemons TE, Milton RC, Klein R, Seddon JM, Ferris Fl (2005) Risk factors for the incidence of Advanced Age-Related Macular Degeneration in the Age-Related Eye Disease Study (AREDS) - AREDS report no. 19. Ophthalmology 112: 533-539. [Crossref]

6. Klein BE, Klein R, Lee KE, Jensen SC (2001) Measures of obesity and age-related eye diseases. Ophthalmic Epidemiol 8: 251-262. [Crossref]

7. Henricsson M, Nyström L, Blohmé G, Östman J, Kullberg C, et al. (2003) The incidence of retinopathy 10 years after diagnosis in young adult people with diabetes: results from the nationwide population-based Diabetes Incidence Study in Sweden (DISS). Diabetes Care 26: 349-354. [Crossref]

8. Rabsilber TM, Khoramnia R, Auffarth GU (2006) Anterior chamber measure-ments using Pentacam rotating Scheimpflug camera. J Cataract Refract Surg 32: 456-459. [Crossref]

9. Kuczmarski RJ, Ogden CL, Grummer-Strawn LM, Flegal KM, Guo SS, et al. (2000) CDC growth charts: United States. Adv Data : 1-27. [Crossref]

10. World Health Organization. World Health Organization Child Growth Standards. 2006

11. Radhakrishnan S, Rollins AM, Roth JE, Yazdanfar S, Westphal V, et al. (2001) Real-time optical coherence tomography of the anterior segment at $1310 \mathrm{~nm}$. Arch Ophthalmol 119: 1179-1185. [Crossref]

12. Prasad A, Fry K, Hersh PS (2011) Relationship of age and refraction to central corneal thickness. Cornea 30: 553-555. [Crossref]

13. Lekskul M, Aimpun P, Nawanopparatskul B, Bumrungsawat S, Trakulmungkijkarn T, et al. (2005) The correlations between Central Corneal Thickness and age, gender intraocular pressure and refractive error of aged 12-60 years old in rural Thai community. J Med Assoc Thai 3: 175-179. [Crossref]

14. Chen MJ, Liu YT, Tsai CC, Chen YC, Chou CK, et al. (2009) Relationship between central corneal thickness, refractive error, corneal curvature, anterior chamber depth and axial length. J Chin Med Assoc 72: 133-137. [Crossref]

15. Eysteinsson T, Jonasson F, Sasaki H, Arnarsson A, Sverrisson T, et al. (2002) Centra corneal thickness, radius of the corneal curvature and intraocular pressure in normal subjects using non-contact techniques: Reykjavik Eye Study. Acta Ophthalmol Scand 80: 11-15. [Crossref]

16. Foster PJ, Alsbirk PH, Baasanhu J, Munkhbayar D, Uranchimeg D, et al. (1997) Anterior chamber depth in Mongolians: variation with age, sex, and method of measurement. Am J Ophthalmol 124: 53-60. [Crossref]

17. Wang X, Wu Q (2013) Investigation of the human anterior segment in norma Chinese subjects using a dual Scheimpflug analyzer. Ophthalmology 120: 703-708. [Crossref]

18. Rüfer F, Schröder A, Klettner A, Frimpong-Boateng A, Roider JB, et al (2010) Anterio chamber depth and iridocorneal angle in healthy White subjects: effects of age, gender and refraction. Acta Ophthalmol 88: 885-890. [Crossref]

19. Yudkin JS, Eringa E, Stehouwer CD (2012) "Vasocrine" signalling from perivascular fat: a mechanism linking insulin resistance to vascular disease. Lancet 365: 1817-1820. [Crossref]

20. Broadway DC, Drance SM (1998) Glaucoma and vasospasm. Br J Ophthalmol 82: 862-870. [Crossref]

21. Harris A, Zarfati D, Zalish M, Biller J, Sheets CW, et al. (2003) Reduced cerebrovascular blood flow velocities and vasoreactivity in open-angle glaucoma. Am J Ophthalmol 135: 144-147. [Crossref]

22. Bulpitt CJ, Hodes C, Everitt MG (1975) Intraocular pressure and systemic blood pressure in the elderly. Br J Ophthalmol 59: 717-720. [Crossref]

23. Shiose Y (1984) The aging effect on intraocular pressure in an apparently normal population. Arch Ophthalmol 102: 883-887. [Crossref] 
24. Shiose Y, Kawase Y (1986) A new approach to stratified normal intraocular pressure in a general population. Am J Ophthalmol 101: 714-721. [Crossref]

25. Krebs NF, Himes JH, Jacobson D, Nicklas TA, Guilday P, et al. (2007) Assessment of child and adolescent overweight and obesity. Pediatrics 120 Suppl 4: S193-228. [Crossref]
26. Stojanov O, Stokic E, Sveljo O, Naumovic N (2013) The influence of retrobulbar adipose tissue volume upon intraocular pressure in obesity. Vojnosanit Pregl 70: 469476. [Crossref]

27. Gunes A, Uzun F, Karaca EE, Kalayc $̈ \pm$ M (2015) Evaluation of Anterior Segment Parameters in Obesity. Korean J Ophthalmol 29: 220-225. [Crossref]

Copyright: (O2019 Koca S. This is an open-access article distributed under the terms of the Creative Commons Attribution License, which permits unrestricted use, distribution, and reproduction in any medium, provided the original author and source are credited. 